\title{
Definition of management zones in coffee production fields based on apparent soil electrical conductivity
}

\author{
Domingos Sárvio Magalhães Valente ${ }^{*}$, Daniel Marçal de Queiroz ${ }^{1}$, Francisco de Assis de Carvalho Pinto ${ }^{1}$, Nerilson Terra Santos², \\ Fábio Lúcio Santos ${ }^{1}$
}

IUFV - Depto. de Engenharia Agrícola, Av. P.H. Rolfs, s/ $\mathrm{n}^{\circ}$, Campus Universitário - 36570-000 - Viçosa, MG - Brasil. 2UFV - Depto. de Estatística.

${ }^{*}$ Corresponding author <valente@ufv.br>

Edited by: José Euclides Stipp Paterniani

\begin{abstract}
Fertilizer application at variable rates requires dense sampling to determine the resulting field spatial variability. Defining management zones is a technique that facilitates the variable-rate application of agricultural inputs. The apparent electrical conductivity of the soil is an important factor in explaining the variability of soil physical-chemical properties. Thus, the objective of this study was to define management zones for coffee (Coffea Arabica L.) production fields based on spatial variability of the apparent electrical conductivity of the soil. The resistivity method was used to measure the apparent soil electrical conductivity. Soil samples were collected to measure the chemical and physical soil properties. The maps of spatial variability were generated using ordinary kriging method. The fuzzy k-means algorithm was used to delimit the management zones. To analyze the agreement between the management zones and the soil properties, the kappa coefficients were calculated. The best results were obtained for the management zones defined using the apparent electrical conductivity of the soil and the digital elevation model. In this case, the kappa coefficient was 0.45 for potassium, which is an element that is associated with quality coffee. The other variable that had a high kappa coefficient was remaining phosphorous; the coefficient obtained was 0.49 . The remaining phosphorus is an important parameter for determining which fertilizers and soil types to study. Keywords: Coffea Arabica L., geostatistics, fuzzy k-means, soil sensors
\end{abstract}

Received February 18, 2011

Accepted January 16, 2012 the important role played by soil electrical parameters in explaining the variability of physical-chemical soil properties and crop yield. This study aimed to define management zones for coffee production fields based on the spatial variability of apparent soil electrical conductivity.

\section{Materials and Methods} trying to find new cultivation methods that can improve yield and reduce production cost. One available technique that can be used for coffee production is precision agriculture, which can help producers to optimize the use of inputs and to identify areas with high productivity and quality potential.

In precision agriculture, determination of the spatial variability of fertilizer dosage requires a dense sampling of the nutrients present in the soil (Yan et al., 2007a). One of the techniques used to reduce the number of required soil samples involves defining management zones based on information that can be collected at a low cost (Moral et al., 2010; Xin-Zhong et al., 2009; Zhang et al., 2010). Generally, the field information used to define management zones is based on maps of apparent soil electrical conductivity, digital elevation models, maps created using remote sensing and yield maps obtained from more than one crop (Fleming et al., 2004).

Some researchers (Corwin and Lesch, 2003; Corwin et al., 2003; Corwin and Lesch, 2005a; Corwin and Lesch, 2005b; Corwin et al., 2006; Kuhn et al., 2009; Lesch et al., 2005; Morari et al., 2009; Moral, et al., 2010; Saey et al., 2009; Yan et al., 2007a; Yan et al., 2007b; Yan et al., 2007c; Yan et al., 2008) have demonstrated

\section{Study area and data collection}

The data for apparent soil electrical conductivity were measured on a farm located in Araponga, state of Minas Gerais, Brazil $\left(20^{\circ} 42^{\prime} 33^{\prime \prime} \mathrm{S}, 42^{\circ} 34^{\prime} 17^{\prime \prime} \mathrm{W}\right.$, average altitude of $913 \mathrm{~m}$ a.s.1.). The farm has 86 ha planted with Coffea arabica L. The farm is located in a hilly area, and the soil is classified as Typic Hapludox (Soil Survey Staff, 2006).

The resistivity method was used to measure the apparent soil electrical conductivity. This method uses four electrodes that are introduced in the surface of the soil. Two configurations of the Wenner Array (Corwin and Lesch, 2003), in which the electrodes are arranged in a line and equally spaced from each other, were used. In one configuration, the distance between the electrodes was $0.2 \mathrm{~m}(\mathrm{CE} 20)$, and in the other, the distance was $0.4 \mathrm{~m}$ (CE40). The apparent soil electrical conductivity was obtained using the portable ERM-02 sensor made by Landviser.

The apparent soil electrical conductivity was determined in 20.20 ha. A total of 141 points was selected for measuring the CE20 and CE40 values (Figure 1). 


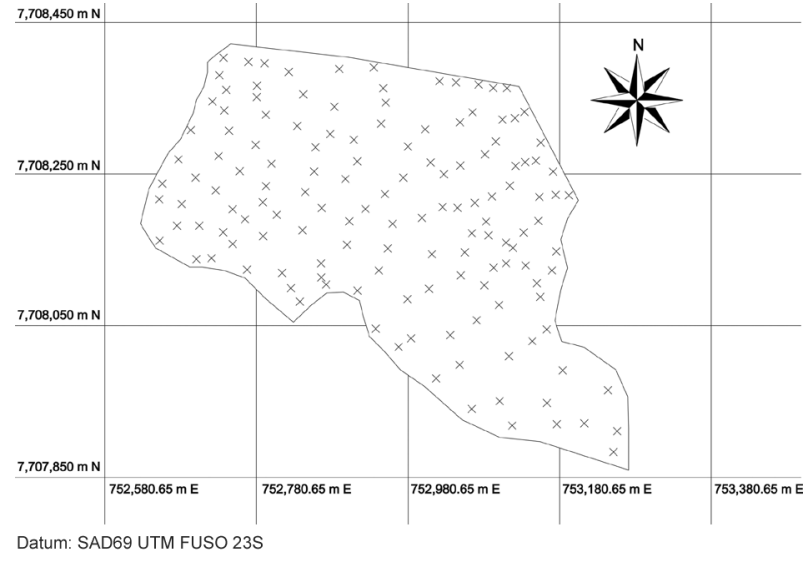

Figure 1 - Locations of points where the apparent soil electrical conductivity was measured.

At each point, a soil sample was collected to measure the chemical and physical soil properties. For each data point, three single samples were collected to compose the sample for soil analysis. Soil samples were analyzed to determine textural composition (clay, silt and sand), electrical conductivity of the saturation extract (1:5), moisture and soil fertility. The following soil fertility properties were analyzed: $\mathrm{pH}$; potential acidity $(\mathrm{H}+\mathrm{Al})$; levels of $\mathrm{P}, \mathrm{K}, \mathrm{Ca}^{2+}, \mathrm{Mg}^{2+}$ and $\mathrm{Al}^{3+}$; sum of the bases $(\mathrm{SB})$; effective cation exchange capacity $\left(\mathrm{CEC}_{\mathrm{t}}\right)$; cation exchange capacity at $\mathrm{pH} 7\left(\mathrm{CEC}_{\mathrm{T}}\right)$; base saturation $(\mathrm{V}) ; \mathrm{Al}^{3+}$ saturation $(\mathrm{m})$; and levels of $\mathrm{Zn}, \mathrm{Fe}, \mathrm{Mn}, \mathrm{Cu}$, remaining phosphorous (Prem) and organic matter (OM).

Each sampled point was georeferenced using the Promark 3 DGPS made by Magellan. For differential correction, data from the Brazilian Network for Continuous Monitoring (RBMC) were used. GNSS solution software (developed by Magellan) was used to process the data.

\section{Methods for management class delineation}

A software named KRIG-ME was implemented using the language Visual Basic, version 6.0. Software was developed considering the follow steps: (i) model the semivariogram; (ii) perform the ordinary kriging to generate maps of spatial variability; (iii) delimit the management zones using a fuzzy k-means algorithm that is based on the maps of spatial variability; (iv) find the optimal number of classes, using the fuzziness performance index (FPI) and the modified partition entropy (MPE) and (v) finally, calculate the kappa coefficient to analyze the how well the management zones represent the variables of a production field.

The first step in this process was to model the semivariogram. So, in order to do this, the experimental semivariogram was calculated using Equation 1 (Isaaks and Srivastava, 1989).

$\hat{\gamma}(h)=\frac{1}{2 N(h)} \sum_{i=1}^{N(h)}\left[Z\left(x_{i}\right)-Z\left(x_{i}+h\right)\right]^{2}$ in which $\hat{\gamma}(h)$ is the experimental semivariance, $\mathrm{Z}\left(x_{i}\right)$ is the variable value at the position $\mathrm{x}_{i} \mathrm{Z}\left(\mathrm{x}_{i+h}\right)$ is the variable value at the position $x_{(i+h)^{\prime}} N(h)$ is the number of pairs of data with a lag distance of $h, i$ is the sample position and $h$ is the distance between samples.

The experimental semivariance was calculated by assuming that spatial dependence was isotropic. The following variogram models were fitted to the experimental data: linear with sill, spherical, Gaussian and exponential. The parameters of each model were obtained using nonlinear regression. The iterative Levenberg-Marquardt method, which consists of a modification of the Gauss-Newton method, was used to adjust for nonlinear functions (Kanzowa et al., 2005).

To use the Levenberg-Marquardt method, it is necessary to establish initial values for the fitting parameters. In this study, the calculated minimum experimental semivariance was set as the initial value for the nugget effect $(\mathrm{C} 0)$. For the value of the semivariance $(\mathrm{C} 1)$, the initial value was set equal to the calculated maximum experimental semivariance minus the nugget effect $(\mathrm{C} 0)$. The initial value of the range (A) was established as the maximum separation distance between all pairs of points.

To choose the model that best fit the experimental data, the sum of squared residuals (SSR) and the coefficient of determination $\left(\mathrm{R}^{2}\right)$ were calculated. The developed system also calculates the spatial dependency index defined as $\mathrm{C} 1 /(\mathrm{C} 0+\mathrm{C} 1)$.

The ordinary kriging method was used to interpolate the variable values according to a uniform grid. All interpolated values were stored in a matrix. Each matrix cell represents one pixel on the map. The size of each pixel, the number of neighbors and the search radius are defined in the software. In this study, the default values were as follows: the pixel size was five by five meters, the minimum number of neighbors was four, the maximum number of neighbors was 16 and the search radius was equal to the range of the variogram model.

The management zones were defined using the interpolated values according to a regular grid by applying the fuzzy k-means algorithm. This method is based on the minimization of Equation 2, as shown in Guastaferro et al. (2010).

$J=\sum_{i=1}^{c} \sum_{j=1}^{n} u_{i j}{ }^{q} d_{i j}{ }^{2}$

subject to:

$\sum_{j=1}^{n} u_{i j}=1$ for $i=1,2,3 \ldots \mathrm{c}$;

$\sum_{i=1}^{c} u_{i j}>0$ for $j=1,2,3 \ldots n$; and

$u_{i j} \in\{0,1\}$. 
In Equation 2, $n$ is the number of data points, $c$ is the number of classes, $u_{i j}$ is the element $(i, j)$ of the membership degree matrix, $d_{i j}$ is the distance between the class centroid $i$ and the grid point $j$ and $q$ is the exponent for fuzzy exponent $(1 \leq q<\infty)$.

To calculate the samples' proximity to one another, the Euclidean distance was used, which normalizes the variables to a mean of zero with a standard deviation of one. All classifications were performed using a maximum of 100 iterations and a fuzzy exponent equal to two.

The management zone maps were generated using different combinations of the altitude, apparent soil electrical conductivity measured from 0.0 to $0.2 \mathrm{~m}$ (CE20), and apparent soil electrical conductivity measured from 0.0 to $0.4 \mathrm{~m}$ (CE40), as shown in Table 1 . The classification was performed with two, three, four and five classes, generating four management zone maps for each set of variable analyzed.

To obtain the optimal number of classes, two indices were determined: the FPI and the MPE. The FPI measures the member degree of separation to different classes. The MPE estimates the degree of disorganization created by the number of classes. The indices of the FPI and the MPE can vary from zero to one. Values near zero indicate distinct classes with few samples of low compliance, whereas values close to one indicate no distinct classes and a large number of samples of low adherence. Thus, the optimal number of classes occurs when the two indices are minimized (Song et al., 2009).

\section{Analytical method for comparing the class map with the soil property map}

To analyze the agreement between the management zones and the soil properties, cross-tabulation between each management zone map and each soil property map with the same number of classes was performed (Kitchen et al., 2005). Thus, tabulations were performed between six maps of management zones and 22 soil property maps.

When the fuzzy k-means algorithm is used, the labeling of classes is random. Therefore, a reclassification of the management zone labels was performed, based on the maximization of the main diagonal of the matrix of cross-tabulation. The Hungarian algorithm for combinatorial optimization was used in this reclassification. After

Table 1 - Listing of the apparent soil electrical conductivity and altitude variable combinations used in fuzzy k-means algorithm to define management zones.

\begin{tabular}{lc}
\hline Management Zone Labels & Variables used \\
\hline ZMA & Altitude \\
ZM20 & CE20 \\
ZM40 & CE40 \\
ZM20A & CE20 and altitude \\
ZM40A & CE40 and altitude \\
ZM2040A & CE20, CE40 and altitude \\
\hline
\end{tabular}

reclassifying the management zone map and calculating the confusion matrix, the kappa coefficient was obtained (Kitchen et al., 2005; Valckx et al., 2009). The kappa coefficient indicates the superiority of the reclassification over a random classification. According to Kitchen et al. (2005), the highest kappa coefficient between the two ratings occurs when the correlation is maximized. Thus, one considered the classes of soil properties to be the true data and the management zone map to be the classifier.

\section{Results and Discussion}

For the ZMA, the FPI was minimized for two classes, and the MPE was minimized for five classes (Figure 2 (a). In this case, when the indices do not give the same optimum number of classes, the final decision regarding the ideal number of classes requires further analysis. It is necessary to verify whether working with a greater number of management zones will result in different yield values among the classes (Fridgen et al., 2004). Moreover, one can compare management zones defined with different input variables to determine which variables are the most important.

The minimum values of the FPI and the MPE for ZM20 and ZM40 maps occurred for two classes (Figures $2(b)$ and 2(c)). For ZM20A, ZM40A and ZM2040A, the minimum value of the FPI and the MPE occurred when three classes were used (Figures 2(d), 2(e) and 2(f)). Molin and Castro (2008), Morari et al. (2009), Yan et al. (2008) and Xin-Zhong et al. (2009) used performance indices for classification and found that the optimum number of classes was three.

The ZMA, ZM20, ZM40, ZM20A, ZM40A and ZM2040A management zones for three classes are shown in Figure 3. These management zone definitions were analyzed to verify whether they agree with the soil property maps. Table 2 shows the mean values of variables in each of the defined management zones.

The kappa coefficients and soil properties for the ZMA, ZM20, ZM40, ZM20A, ZM40A and ZM2040A management zones, which are grouped according to three classes, are shown in Table 3. The kappa coefficient can be interpreted as follows (Landis and Koch, 1977): values from 0.00 to 0.20 indicate poor agreement, values from 0.20 to 0.40 indicate fair agreement, values from 0.40 to 0.50 indicate moderate agreement, values from 0.50 to 0.80 indicate good agreement and values from 0.80 to 1.00 indicate almost perfect agreement. The higher values of kappa coefficients obtained were classified as moderate agreement. Among them, the kappa coefficient of soil zinc content for the ZMA management zones was significantly greater than those for the other management zones. For soil potassium, remaining phosphorus, copper, iron, exchangeable acidity, $\mathrm{Al}^{3+}$ saturation and silt properties, the kappa coefficients were also considered moderate, and the higher kappa coefficient values were obtained for the ZM20 management 

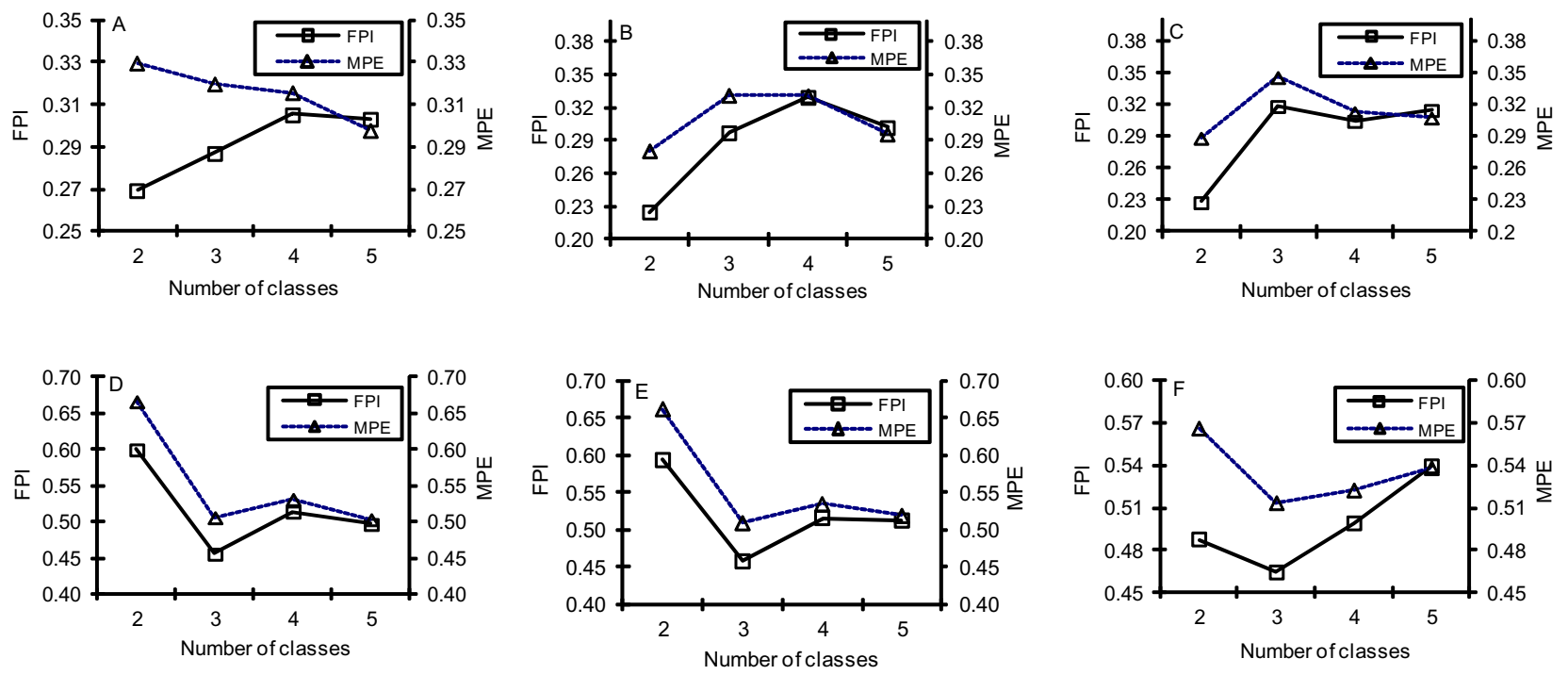

Figure 2 - The Fuzziness performance index (FPI) and modified partition entropy (MPE) calculated for the management zones A) ZMA, B) ZM20, C) ZM40, D) ZM20A, E) ZM40A and F) ZM2040A.
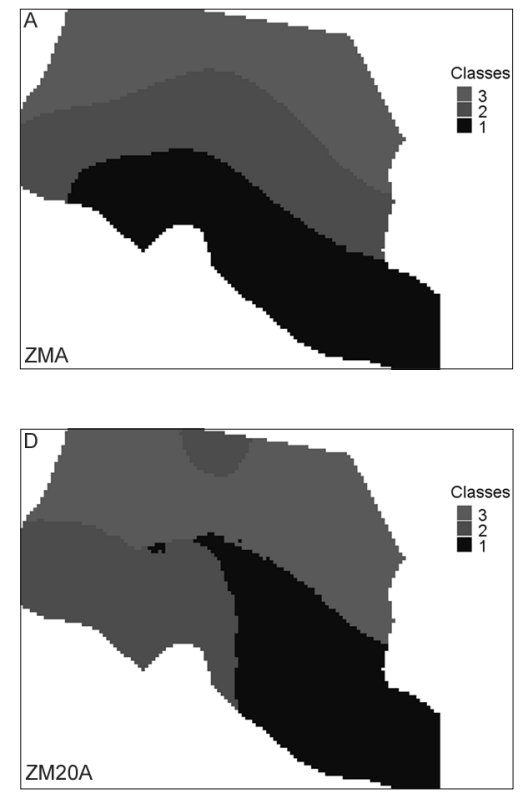
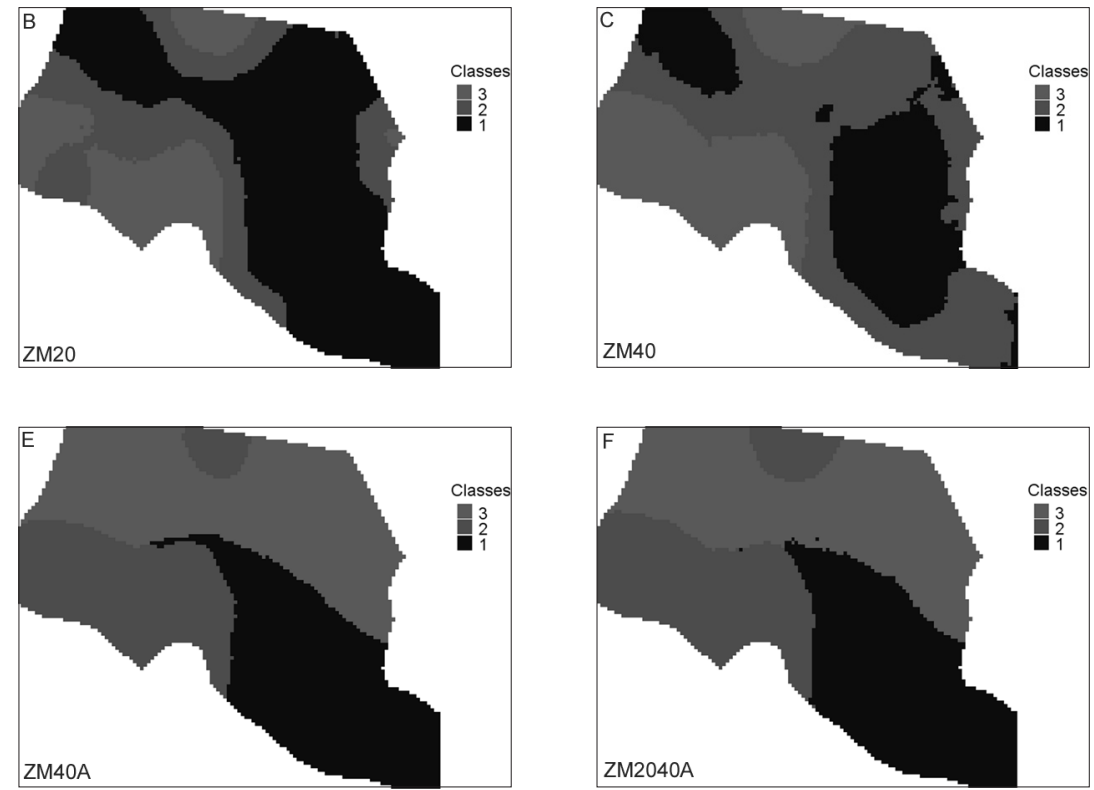

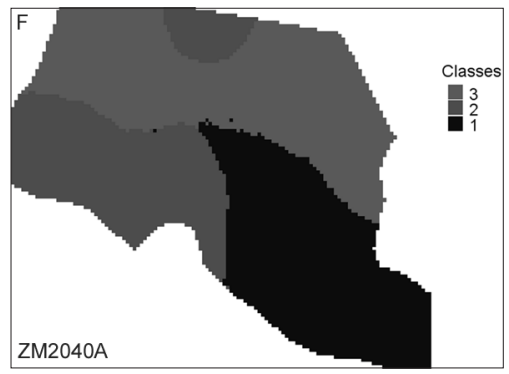

Figure 3 - Management zones with three classes, defined by mapping the spatial variability of A) altitude (ZMA), B) CE20 (ZM20), C) CE40 (ZM40), D) CE20 and altitude (ZM2OA), E) CE40 and altitude (ZM40A) and F) CE20, CE40 and altitude (ZM2040A).

zones. For these properties, the kappa coefficients for the ZM40A management zones were statistically equal to those for the ZM20A management zones. The kappa coefficients for the ZM2040A management zones were not different of the kappa coefficients for the ZM20A management zones, with the exception of soil iron content, for which the kappa coefficients for the ZM2040A management zones were statistically lower than the ZM20A and ZM40A management zones.
ZM20A, ZM40A and ZM2040A management zones did not produce any values of the kappa coefficients lower than those obtained with the ZM20, ZM40 and ZMA management zones. In addition, the kappa coefficients for the ZM2040A management zones were not greater than those for any other management zone. Based on this information, the ZM20A and ZM40A management zones were the best choice for classification of soil properties. 
Table 2 - Mean and standard deviation of the altitude, apparent electrical conductivity of 0.0 to $0.2 \mathrm{~m}$ (CE20) and apparent electrical conductivity of soil 0.0 to $0.4 \mathrm{~m}$ (CE40) for the defined management zones.

\begin{tabular}{|c|c|c|c|c|c|c|c|}
\hline \multirow{2}{*}{ Management zones } & \multirow{2}{*}{ Classes } & \multicolumn{2}{|c|}{ Altitude (m) } & \multicolumn{2}{|c|}{ CE20 (mS m $\left.{ }^{-1}\right)$} & \multicolumn{2}{|c|}{ CE40 (mS m-1) } \\
\hline & & Mean & Standard deviation & Mean & Standard deviation & Mean & Standard deviation \\
\hline & 1 & 869.0 & 10.33 & - & - & - & - \\
\hline \multirow[t]{3}{*}{ ZMA } & 2 & 909.0 & 11.80 & - & - & - & - \\
\hline & 3 & 948.7 & 12.01 & & & & \\
\hline & 1 & - & - & 1.48 & 0.13 & - & - \\
\hline \multirow[t]{3}{*}{ ZM20 } & 2 & - & - & 1.94 & 0.15 & - & - \\
\hline & 3 & - & - & 2.46 & 0.21 & - & - \\
\hline & 1 & - & - & - & - & 0.94 & 0.08 \\
\hline \multirow[t]{3}{*}{ ZM40 } & 2 & - & - & - & - & 1.17 & 0.09 \\
\hline & 3 & - & - & - & - & 1.61 & 0.14 \\
\hline & 1 & 877.0 & 17.11 & 1.48 & 0.16 & - & - \\
\hline \multirow[t]{3}{*}{ ZM20A } & 2 & 891.9 & 26.29 & 2.34 & 0.26 & - & - \\
\hline & 3 & 940.7 & 17.40 & 1.64 & 0.24 & - & - \\
\hline & 1 & 876.9 & 17.21 & - & - & 1.03 & 0.12 \\
\hline \multirow[t]{3}{*}{ ZM40A } & 2 & 892.3 & 26.14 & - & - & 1.60 & 0.15 \\
\hline & 3 & 940.7 & 17.39 & - & - & 1.12 & 0.16 \\
\hline & 1 & 877.4 & 17.61 & 1.48 & 0.16 & 1.02 & 0.12 \\
\hline \multirow[t]{2}{*}{ ZM2040A } & 2 & 894.9 & 28.23 & 2.34 & 0.25 & 1.60 & 0.15 \\
\hline & 3 & 940.4 & 18.12 & 1.63 & 0.21 & 1.11 & 0.14 \\
\hline
\end{tabular}

Table 3 - Kappa coefficients calculated from the classification of soil properties with the management zones in three classes.

\begin{tabular}{|c|c|c|c|c|c|c|}
\hline \multirow{2}{*}{ Soil properties } & \multicolumn{6}{|c|}{ Management zones } \\
\hline & ZMA & ZM20 & ZM40 & ZM20A & ZM40A & ZM2040A \\
\hline Clay content & $0.18^{a}$ & $0.13^{b}$ & $0.16^{\mathrm{a}}$ & $0.16^{a}$ & $0.17^{a}$ & $0.18^{a}$ \\
\hline $\mathrm{CEC}_{t}$ & $0.21^{\mathrm{a}}$ & $0.28^{b}$ & $0.19^{a}$ & $0.35^{d}$ & $0.36^{d}$ & $0.36^{d}$ \\
\hline $\mathrm{CEC}_{\mathrm{T}}$ & $0.20^{\mathrm{a}}$ & $0.11^{\mathrm{b}}$ & $0.09^{b}$ & $0.22^{\mathrm{a}}$ & $0.22^{\mathrm{a}}$ & $0.20^{\mathrm{a}}$ \\
\hline K & $0.17^{a}$ & $0.38^{b}$ & $0.39^{b}$ & $0.45^{d}$ & $0.44^{\mathrm{d}}$ & $0.46^{d}$ \\
\hline Organic matter & $0.18^{a}$ & $0.07^{\mathrm{b}}$ & $0.09^{b}$ & $0.13^{d}$ & $0.13^{\mathrm{d}}$ & $0.14^{d}$ \\
\hline$P$ & $0.23^{a}$ & $0.12^{\mathrm{b}}$ & $0.13^{b}$ & $0.29^{d}$ & $0.29^{d}$ & $0.27^{d}$ \\
\hline Remaining phosphorus & $0.26^{a}$ & $0.15^{b}$ & $0.25^{\mathrm{a}}$ & $0.49^{d}$ & $0.48^{d}$ & $0.49^{d}$ \\
\hline $\mathrm{pH}$ & $0.30^{a}$ & $0.09^{\mathrm{b}}$ & $0.11^{\mathrm{b}}$ & $0.26^{d}$ & $0.26^{d}$ & $0.26^{d}$ \\
\hline $\mathrm{Cu}$ & $0.38^{a}$ & $0.10^{\mathrm{b}}$ & $0.16^{c}$ & $0.53^{d}$ & $0.52^{\mathrm{d}}$ & $0.52^{\mathrm{d}}$ \\
\hline $\mathrm{Fe}$ & $0.27^{a}$ & $0.00^{\circ}$ & $0.13^{c}$ & $0.42^{d}$ & $0.42^{\mathrm{d}}$ & $0.39^{t}$ \\
\hline $\mathrm{Ca}^{2+}$ & $0.20^{\mathrm{a}}$ & $0.13^{b}$ & $0.12^{b}$ & $0.25^{d}$ & $0.26^{d}$ & $0.27^{d}$ \\
\hline $\mathrm{Mg}^{2+}$ & $0.39^{a}$ & $0.16^{\mathrm{b}}$ & $0.13^{c}$ & $0.39^{a}$ & $0.39^{a}$ & $0.37^{a}$ \\
\hline Exchangeable acidity & $0.37^{a}$ & $0.07^{b}$ & $0.14^{c}$ & $0.43^{d}$ & $0.43^{d}$ & $0.41^{d}$ \\
\hline Potential acidity & $0.30^{a}$ & $0.05^{\mathrm{b}}$ & $0.15^{c}$ & $0.18^{d}$ & $0.17^{c}$ & $0.16^{c}$ \\
\hline Sum of bases & $0.24^{a}$ & $0.22^{\mathrm{a}}$ & $0.15^{c}$ & $0.33^{d}$ & $0.33^{d}$ & $0.33^{d}$ \\
\hline Base saturation & $0.37^{a}$ & $0.03^{b}$ & $0.07^{c}$ & $0.21^{d}$ & $0.21^{d}$ & $0.20^{d}$ \\
\hline $\mathrm{Al}^{+3}$ saturation & $0.28^{a}$ & $0.21^{\mathrm{b}}$ & $0.17^{c}$ & $0.49^{d}$ & $0.49^{d}$ & $0.48^{d}$ \\
\hline $\mathrm{Zn}$ & $0.52^{\mathrm{a}}$ & $0.19^{\mathrm{b}}$ & $0.22^{c}$ & $0.48^{d}$ & $0.47^{d}$ & $0.45^{\mathrm{e}}$ \\
\hline $\mathrm{Mn}$ & $0.21^{\mathrm{a}}$ & $0.28^{b}$ & $0.17^{c}$ & $0.38^{d}$ & $0.37^{d}$ & $0.36^{d}$ \\
\hline Coarse sand & $0.31^{\mathrm{a}}$ & $0.06^{b}$ & $0.11^{c}$ & $0.30^{\mathrm{a}}$ & $0.29^{a}$ & $0.29^{a}$ \\
\hline Fine sand & $0.21^{\mathrm{a}}$ & $0.01^{\circ}$ & $0.09^{c}$ & $0.14^{d}$ & $0.10^{c}$ & $0.15^{d}$ \\
\hline Silt & $0.38^{a}$ & $0.19^{\mathrm{b}}$ & $0.26^{c}$ & $0.49^{d}$ & $0.50^{\mathrm{d}}$ & $0.48^{d}$ \\
\hline
\end{tabular}

${ }^{*}$ Not significant at $5 \%$ probability; a, b, c, d, e indicating that the values are different among management zones, horizontally $(p<0.05)$.

The soil clay content map did not yield a high kappa coefficient for any of the defined management zones. The maximum kappa coefficient for this property was 0.18 . However, the kappa coefficient between the ZM20A management zones and remaining phosphorus was 0.49 , which indicates moderate agreement. Remaining phosphorus is an important parameter for defining the fertilizer dosage recommendation (Donagemma et al., 2008). The highest values of the kappa coefficient when using the ZM20A management zone for potassium and phosphorus were 0.46 and 0.29 , respectively.

Silva et al. (2002a;b) have highlighted the importance of potassium to the quality of a coffee beverage. The result obtained in the present work suggests, there- 
fore, that the apparent soil electrical conductivity may be useful for defining management zones to obtain better coffee quality.

The kappa coefficients between the ZM20A management zones and zinc, copper, iron and manganese soil micronutrients content were higher than 0.38. Kitchen et al. (2005) obtained kappa coefficients ranging from 0.25 to 0.43 in two production fields. These results were obtained using three variables to define management zones. When they defined management zones using altitude and the apparent electrical conductivity of the soil at a defined depth, the kappa coefficients they obtained ranged from 0.24 to 0.36 .

The results obtained by Kitchen et al. (2005) and the ones obtained in the present work suggest that more than one variable should be used for the definition of management zones. Moreover, the apparent soil electrical conductivity and altitude are a good choices for defining management zones that can be used to classify soil properties.

\section{Acknowledgements}

To the Foundation for Research Financial Support of the Minas Gerais State, Brazil (FAPEMIG), and the National Council for Scientific and Technological Development $(\mathrm{CNPq})$ of Brazil for their financial support of this research.

\section{References}

Corwin, D.L.; Lesch, S.M. 2005b. Characterizing soil spatial variability with apparent soil electrical conductivity. Part II. Case study. Computer and Electronics in Agriculture 46: 135152.

Corwin, D.L.; Lesch, S.M.; Oster, J.D.; Kaffka, S.R. 2006. Monitoring management-induced spatio-temporal changes in soil quality through soil sampling directed by apparent electrical conductivity. Geoderma 131: 369-387.

Corwin, D.L.; Lesch, S.M.; Shouse, P.J.; Soppe, R.; Ayars, J.E. 2003. Identifying soil properties that influence cotton yield using soil sampling directed by apparent soil electrical conductivity. Agronomy Journal 95: 352-364.

Corwin, D.L.; Lesh, S.M. 2005a. Apparent soil electrical conductivity measurements in agricultural. Computers and Electronics in Agriculture 46: 11-43.

Corwin, D.L.; Lesch, S.M. 2003. Application of soil electrical conductivity to precision agriculture: theory, principles, and guidelines. Agronomy Journal 95: 471-471.

Donagemma, G.K.; Ruiz, H.A.; Alvarez V., V.H.; Ker, J.C.; Fontes, M.P.F. 2008. Solution equilibrium phosphorus in clay and silt fractions of oxisols after particle size analysis pre-treatments. Revista Brasileira de Ciência do Solo 32: 1785-1791 (in Portuguese, with abstract in English).

Fleming, K.L.; Heermann, D.F.; Westfall, D.G. 2004. Evaluating soil color with farmer input and apparent soil electrical conductivity for management zone delineation. Agronomy Journal 96: 1581-1587.
Fridgen, J.J.; Kitchen, N.R.; Sudduth, K.A.; Drummond, S.T.; Wiebold, W.J.; Fraisse, C.W. 2004. Management zone analyst (MZA): software for subfield management zone delineation. Agronomy Journal 96: 100-108.

Guastaferro, F.; Benedetto, D.; Sollitto, D.; Troccoli, A.; Cafarelli, B.A. 2010. Comparison of different algorithms for the delineation of management zones. Precision Agriculture 11: 600-620.

Isaaks, E.H.; Srivastava, R.M. 1989. An Introduction to Applied Geostatistics. Oxford University Press, New York, NY, USA.

Kanzowa, C.; Yamashitab, N.; Fukushimab, M. 2005. LevenbergMarquardt methods with strong local convergence properties for solving nonlinear equations with convex constraints. Journal of Computational and Applied Mathematics 173: 321-343.

Kitchen, N.R.; Sudduth, K.A.; Myers, D.B.; Drummond, S.T.; Hong, S.Y. 2005. Delineating productivity zones on claypan soil fields using apparent soil electrical conductivity. Computer and Electronics in Agriculture 46: 285-308.

Kuhn, J.; Brenning, A.; Wehrhan, M.; Koszinski, S.; Sommer, M. 2009. Interpretation of electrical conductivity patterns by soil properties and geological maps for precision agriculture. Precision Agriculture 10: 490-507.

Landis, J.R.; Koch, G.G. 1977. The measurement of observer agreement for categorical data. Biometrics 33: 159-174.

Lesch, S.M.; Corwin, D.L.; Robinson, D.A. 2005. Apparent soil electrical conductivity mapping as an agricultural management tool in arid zone soils. Computer and Electronics in Agriculture 46: 351-378.

Molin, J.P.; Castro, C.N. 2008. Establishing management zones using soil electrical conductivity and other soil properties by the fuzzy clustering technique. Scientia Agricola 65: 567573.

Moral, F.J.; Terrón, J.M.; Silva, J.R.M. 2010. Delineation of management zones using mobile measurements of soil apparent electrical conductivity and multivariate geostatistical techniques. Soil \& Tillage Research 106: 335-343.

Morari, F; Castrignanò, A.; Pagliarin, C. 2009. Application of multivariate geostatistics in delineating management zones within a gravelly vineyard using geo-electrical sensors. Computers and Electronics in Agriculture 68: 97-107.

Saey, T.; Van, M.; Vermeersch, H.; Ameloot, N.; Cockx, L. 2009. A Pedotransfer function to evaluate the soil profile textural heterogeneity using proximally sensed apparent electrical conductivity. Geoderma 150: 389-395.

Silva, E.B.; Nogueira, F.D.; Guimarães, P.T.G. 2002a. Potassium fertilization and the quality of processed coffee beans. Scientia Agricola 59: 173-179 (in Portuguese, with abstract in English).

Silva, E.B.; Nogueira, F.D.; Guimarães, P.T.G. 2002b. Quality of the coffee grains in function of doses potassium. Acta Scientiarum Agronomy 24: 1291-1297 (in Portuguese, with abstract in English).

Soil Survey Staff. 2006. Keys to Soil Taxonomy. 10ed. USDA/ NCRS, Washington, D.C., USA.

Song, X.; Wang, J.; Huang, W.; Liu, L.; Yan, G.; Pu, R. 2009. The delineation of agricultural management zones with high resolution remotely sensed data. Precision Agriculture 10: 471-487. 
Valckx, J.; Cockx, L.; Wauters, J.; Van, M.; Gevers, G.; Hermy, M.; Muys, B. 2009. Within-field spatial distribution of earthworm populations related to species interactions and soil apparent electrical conductivity. Applied Soil Ecology 41: 315-328.

Xin-Zhong, W.; Guo-Shuna, L.; Hong-Chao, H.; Zhen-Haib, W.; Qing-Huab, L.; Xu-Fengc, L.; Wei-Hongc, H.; Yan-Taoc, L. 2009. Determination of management zones for a tobacco field based on soil fertility. Computers and Electronics in Agriculture 65: 168-175.

Yan, L.; Zhou, S.; Ci-Fang, W.; Fang, L.; Hong-Yi, L. $2007 \mathrm{~b}$. Optimised spatial sampling scheme for soil electrical conductivity based on variance quad-tree (VQT) method. Agricultural Sciences in China 6: 1463-1471.

Yan, L.; Zhou, S.; Ci-Fang, W.; Hong-YI, L; Fang, L. 2008. Determination of potential management zones from soil electrical conductivity, yield and crop data. Journal of Zhejiang University Science B (Biomedicine \& Biotechnology) 9: 68-76.
Yan, L.; Zhou, S.; Feng, L. 2007a. Delineation of site-specific management zones based on temporal and spatial variability of soil electrical conductivity. Soil Science Society of China 17: 156-164.

Yan, L.; Zhou, S.; Feng, L.; Hong-Yi, L. 2007c. Delineation of sitespecific management zones using fuzzy clustering analysis in a coastal saline land. Computers and Electronics in Agriculture 56: $174-186$.

Zhang, X.; Shi, L.; Jia, X.; Seielstad, G.; Helgason, C. 2010. Zone mapping application for precision-farming: a decision support tool for variable rate application. Precision Agriculture 11: 103-114. 